\title{
International and Absolute Electrical Units
}

\begin{abstract}
$\Delta \mathrm{T}$ the recent meeting in Paris of the International Committee of Weights and Measures, the subjoined draft memorandum relating to international and practical absolute electrical units was approved for publication. The document makes clear the position of the Committee and shows that for practically all engineering purposes the change to the suggested now units involves no difficulty.
\end{abstract}

I. In accordance with the authority and responsibility placed upon it by the General Conference of Weights and Measures in 1933, the International Committee of Weights and Measures has decided that the actual substitution of the absolute system of electrical units for the international system shall take place on January 1, 1940.

2. In collaboration with the national physical laboratories the Committee is actively engaged in establishing the ratios between the international units and the corresponding practical absolute units.

3. The Committee directs attention to the fact that it is not at all necessary for any existing electrical standard to be altered or modified with a view to making its actual value conform with the new units. For the majority of engineering applications the old values of the international standards will be suffi- ciently close to the new for no change even of a numerical nature to be required. If for any special reason a higher precision is necessary numerical corrections can always be applied.

4. The following table gives a provisional list of the relations between the international units and the corresponding absolute practical units, to the fourth decimal place. Since differences exist between the standards of the international units held by the various national laboratories affecting the fifth decimal place, and, further, because all the labora. tories which have undertaken determinations of the values of their standards in absolute measure have not yet obtained final results, the Committee does not consider it desirable for the present to seek a higher precision. At the same time it hopes that it will be possible to extend the table of these ratios with a close approximation to the fifth decimal place well before the date fixed for the actual substitution of the practical absolute system for the international system.

1 Ampere international
1 Coulomb ,"
1 Ohm
1 Volt
1 Henry
1 Farad
1 Weber ",
1 Watt

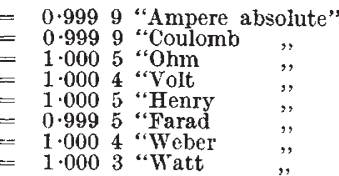

\section{Sixth International Congress of Entomology}

$\mathrm{T}^{\mathrm{n}}$ HE Sixth International Congress of Entomology, attended by some four hundred delegates, was held at Madrid on September 6-12. On account of the financial restrictions, some of the mid-European countries were not so fully represented as at past Congresses, but despite these difficulties, entomologists from practically every country were present. The opening session had as its chairman His Excellency the President of the Spanish Republic, who greatly impressed the Congress by his personality and warm welcome.

The Congress itself was presided over by that veteran entomologist, Dr. I. Bolivar Urrutia, director of the Museo Nacional de Ciencias Naturales, Madrid. A heavy programme, divided into sections devoted to general, ecological, agricultural, forest, medical and veterinary entomology, with, in addition, sessions allotted to apiculture and nomenclature, provided something of interest for everyone, and oonsidering the warm weather and the variety of languages in which the papers were presented, the meetings were very well attended. As these papers will be published and may then be read and digested in the quiet of the study, it is unnecessary to detail them severally by name here, but we might say that some of the illustrated ones, as, for example, Dr. F. W. Edwards's account of the British Museum Expedition to Ruwenzori, Dr. B. Mayne's film of the life-cycle of the malarial parasite in the body of the mosquito,
Dr. Escalera's one on apiculture, and Dr. Kamal's 'talkie' of Prodenia littoralis seemed to be much enjoyed. The Sunday sessions were held at El Escorial, and though most of the delegates spent their time exploring the beautiful and historic buildings and collecting their favourite families of insects in the neighbourhood, the meetings were well attended by the more enthusiastic seekers after knowledge.

Only a small part of the time, however, was devoted to serious scientific matters. The President of the Republic received and entertained the Congress at the Palace, and entomologists must have felt just a little awed on walking up the grand staircase between the lines of fully-accoutred lifeguards; the Mayor of Madrid entertained it to music, and during the subsequent proceedings, outlined to some of the members in excellent English the town-planning schemes of the city; the organisers, to a charming fiesta of Spanish art, to lunches and merienda and a final evening banquet, and bore the expenses of excursions to such historic places as El Pardo, El Escorial (as mentioned above) and Toledo. A whole day was devoted to a sight-seeing trip to the Guadarramas, the Alpine Biological Station being visited en route, the Forest of Valsain, San Ildefonso (La Granja) and Segovia, where members gazed with delight on the beautiful west façade of the cathedral lit up by the setting sun. An afternoon visit to 